\title{
ORIGINAL
}

ARTICLES

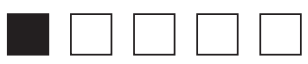

\section{Awareness and Attitudes Around the New Subspecialty Within Ob/Gyn Called Complex Family Planning: A CERA Survey of Family Medicine Chairs}

Grace Shih, MD, MAS; Justine P. Wu, MD, MPH; Diane M. Harper, MD, MPH

\begin{abstract}
BACKGROUND AND OBJECTIVES: Family physicians play an important role in delivery of family planning services, but many factors impact scope of practice. One important factor is the development of subspecialties, such as the new subspecialty within obstetrics and gynecology called complex family planning (CFP).
\end{abstract}

METHODS: In 2019, we conducted a survey of family medicine department chairs as part of the Council of Academic Family Medicine Educational Research Alliance survey. We used descriptive statistics and logistic regression to test for associations between program and chair characteristics, knowledge of CFP, and attitudes regarding family planning services (complex contraceptive counseling, pregnancy options counseling, first trimester miscarriage management, and pregnancy termination).

RESULTS: The survey response rate was $54 \%$ (105/193). Only $8 \%$ of respondents were aware of the CFP subspecialty. The majority of chairs considered all queried family planning services as part of family medicine's scope of practice, including pregnancy termination by medication abortion $(77 \%)$ and by uterine aspiration (60\%). Chairs of departments with a faculty champion in family planning had higher odds of advocating for all queried family planning services as part of family medicine scope of practice (OR 3.0, 1.1-8.2) than those without a faculty champion.

CONCLUSIONS: Few chairs are aware of the new subspecialty of CFP, but most would advocate to maintain some form of abortion care in family medicine's scope of practice. Given family medicine's role in the health care safety net, supporting faculty champions in family planning is important to preserve access to family planning services for marginalized communities.

(Fam Med. 2020;52(10):702-6.)

doi: 10.22454/FamMed.2020.157121

$\mathbf{E}$ ffective June 13, 2020 the Accreditation Council of Graduate Medical Education (ACGME), approved a new subspecialty within obstetrics and gynecology (Ob/Gyn) called complex family planning (CFP). ${ }^{1}$ From CFP's approved program requirements, a cialist is an obstetrician/gynecologist who provides consultation services and comprehensive care for women with complex reproductive health needs." CFP's ACGME competencies include skills that overlap with those of family physicians, such as contraceptive counseling for patients with complex medical or psychosocial conditions, pregnancy options counseling for routine and complex patients, management of abnormal first trimester pregnancy, medication abortion, and first trimester abortion. There has been debate within the family planning community about the implications of the CFP subspecialty, particularly to what extent future policies may restrict nonsubspecialists' ability to provide family planning services. ${ }^{3,4}$

Department chairs play an instrumental role in defining and maintaining family medicine's scope of practice. In this study, we describe awareness of the new CFP subspecialty among US family medicine department chairs. We describe chair perspectives and attitudes regarding family medicine's scope of practice within family planning and assess their intention to advocate for provision of family planning services within family medicine.

\section{Methods}

Surveys were sent by email to chairs of family medicine departments as part of a larger survey conducted by the Council of Academic Family
From the Department of Family Medicine, University of Washington, Seattle, WA (Dr Shih); and Department of Family Medicine, University of Michigan, Ann Arbor, MI (Drs Wu and Harper). 
Medicine Educational Research Alliance (CERA). The survey was conducted utilizing the standard CERA survey methodology. ${ }^{5}$ The American Academy of Family Physicians Institutional Review Board approved the project in August 2019 and data were collected from August 2019 to October 2019.

The target survey population was US family medicine department chairs as identified by the Association of Departments of Family Medicine. Email invitations to participate were delivered with the survey utilizing the online program Survey Monkey. Four follow-up emails to encourage nonrespondents to participate were sent after the initial email invitation.

We used Stata 15.1 (College Station, TX) for all analyses. For this study, we defined family planning services as complex contraceptive counseling, pregnancy options counseling, first trimester miscarriage management, pregnancy termination by medication abortion, and pregnancy termination by uterine aspiration. We refer to this group of services as "queried family planning services." We used univariate categorical statistics to describe (a) demographic characteristics of the programs (program type, geographic region, community size, access to pregnancy termination services); (b) characteristics of the department chairs (gender, race, length of time as chair); (c) perceived relationship with Ob/Gyn department; (d) presence of faculty champion in the area of family planning; and (e) access to pregnancy termination services. The outcome variables were (a) the chair's awareness of CFP subspecialty proposal (yes/no); (b) agreement that queried family planning services are within the scope of family medicine (yes/no); (c) the chair's intention to advocate for scope of practice (yes/no). Appendix 1 shows the family planning survey questions. We hypothesized that outcome variables may be associated with perceived relationship with $\mathrm{Ob} /$ Gyn department, presence of faculty champion in family planning, and access to pregnancy termination services. We tested our hypotheses using $\chi^{2}$ comparisons and conducted multivariate logistic regression controlling for hypothesized outcome variables. We set $\alpha$ at 0.05 .

\section{Results}

Two hundred department chairs were identified at the time of the survey. One email could not be delivered, and six chairs had opted out of SurveyMonkey surveys. The final sample size for department chairs was 193. The response rate for the survey was $54.4 \%$ (105/193). Descriptive statistics of program and chair characteristics are listed in Table 1. Chair respondents came from a variety of residency types, geographic locations, and community sizes. Respondents were mostly white (79\%), male $(61 \%)$, and over 60 years old (47\%). Most chairs (68\%) reported a very good or good relationship with their Ob/Gyn department and 76\% reported presence of a family medicine faculty champion in the area of family planning.

Outcome variables are outlined in Table 2. Only $8 \%$ of respondents were aware of the proposed CFP subspecialty. The majority of chairs considered all queried family planning services part of family medicine's scope of practice, including pregnancy termination by medication abortion (77\%) and by uterine aspiration (60\%). Almost half of the respondents would advocate for all queried family planning services to be part of family medicine's scope of practice. The majority of chairs (73\%) reported that referral to another clinic less than 50 miles away was required to access pregnancy termination services, with some able to provide pregnancy termination at their main residency outpatient site (17\%), and others requiring referral to a clinic 50 or more miles away (10\%).

Associations between program and chair characteristics and outcome variables were insignificant except for relationship between presence of a faculty champion in family planning and select outcome variables (Table 3). Chairs reporting the presence of a faculty champion in family planning had higher odds of considering miscarriage management as part of family medicine's scope of practice (OR 12.8, 2.3-69.8), and higher odds of advocating for all queried family planning services as part of family medicine scope of practice (OR 3.0, 1.1-8.2) than those without a faculty champion. Geographic location of program, community size served, relationship with $\mathrm{Ob} / \mathrm{Gyn}$, and access to pregnancy termination were not associated with chairs' perspectives on scope of practice for family planning services or their intention to advocate for family medicine's scope of practice regarding family planning services.

\section{Discussion}

Nearly all chair respondents considered complex contraceptive counseling, pregnancy options counseling, and miscarriage management to be part of the scope of family medicine. These attitudes are consistent with current ACGME program requirements for family medicine, which state that "residents must have at least 100 hours (or 1 month) or 125 patient encounters dedicated to the care of women with gynecologic issues, including well-woman care, family planning, contraception, and options counseling for unintended pregnancy." 6

Our finding that the majority of chair respondents felt that abortion care falls within the scope of family medicine reflects growing recognition of abortion in our specialty. In 2007, a cross-sectional survey of program directors and chief residents found that $56 \%$ of program directors and $48 \%$ of chief residents agreed that providing first-trimester abortions is within the scope of family medicine. ${ }^{7}$ For comparison, in our study $77 \%$ and $60 \%$ of chair respondents agreed that medication abortion and uterine aspiration, respectively, were part of scope of family medicine practice. Within the past 
Table 1: Characteristics of Chair Respondents and Their Associated Programs

\begin{tabular}{|c|c|}
\hline Characteristics & n (\%) \\
\hline \multicolumn{2}{|l|}{ Program Characteristics } \\
\hline $\begin{array}{l}\text { Type of residency program } \\
\text { Medical school based } \\
\text { Community based }\end{array}$ & $\begin{array}{l}\mathrm{N}=105 \\
46(54) \\
38(45)\end{array}$ \\
\hline $\begin{array}{l}\text { Age of residency program } \\
25 \text { years or less } \\
26-50 \text { years } \\
50+\text { years }\end{array}$ & $\begin{array}{l}\mathrm{N}=105 \\
17(21) \\
59(72) \\
6(7)\end{array}$ \\
\hline $\begin{array}{l}\text { Geographic region of program } \\
\text { New England } \\
\text { Mid and South Atlantic } \\
\text { Midwest } \\
\text { South } \\
\text { Pacific }\end{array}$ & $\begin{array}{l}\mathrm{N}=105 \\
6(6) \\
41(39) \\
27(26) \\
16(15) \\
15(14)\end{array}$ \\
\hline $\begin{array}{l}\text { Community size } \\
\quad<75,000 \\
75,000-149,999 \\
150,000-499,999 \\
500,000-1 \text { million } \\
>1 \text { million }\end{array}$ & $\begin{array}{l}\mathrm{N}=105 \\
15(15) \\
15(15) \\
26(27) \\
16(16) \\
26(27)\end{array}$ \\
\hline $\begin{array}{l}\text { Family medicine department relationship with Ob/Gyn } \\
\text { Very good/good } \\
\text { Acceptable } \\
\text { Poor }\end{array}$ & $\begin{array}{l}\mathrm{N}=82 \\
56(68) \\
20(24) \\
6(7)\end{array}$ \\
\hline $\begin{array}{l}\text { Presence of family medicine faculty champion in family planning } \\
\text { Yes }\end{array}$ & $\begin{array}{l}\mathrm{N}=88 \\
67(76)\end{array}$ \\
\hline $\begin{array}{l}\text { Access to pregnancy termination services } \\
\text { At main residency outpatient clinic } \\
\text { Refer to clinic }<50 \text { miles away } \\
\text { Refer to clinic }>50 \text { miles away }\end{array}$ & $\begin{array}{l}\mathrm{N}=60 \\
10(17) \\
44(73) \\
6(10)\end{array}$ \\
\hline \multicolumn{2}{|l|}{ Chair Characteristics } \\
\hline $\begin{array}{l}\text { Gender } \\
\text { Female } \\
\text { Male } \\
\text { Choose not to disclose }\end{array}$ & $\begin{array}{l}\mathrm{N}=105 \\
35(35) \\
61(61) \\
3(3)\end{array}$ \\
\hline $\begin{array}{l}\text { Race } \\
\text { Asian } \\
\text { Black } \\
\text { White } \\
\text { Choose not to disclose }\end{array}$ & $\begin{aligned} \mathrm{N} & =105 \\
7 & (7) \\
6 & (6) \\
77 & (79) \\
8 & (8)\end{aligned}$ \\
\hline $\begin{array}{l}\text { Age } \\
20-49 \text { years } \\
50-59 \text { years } \\
>60 \text { years }\end{array}$ & $\begin{array}{l}\mathrm{N}=105 \\
16(16) \\
36(36) \\
47(47)\end{array}$ \\
\hline $\begin{array}{l}\text { Years as department chair } \\
\leq 1 \text { year } \\
1-5 \text { years } \\
6-10 \text { years } \\
\geq 11 \text { years }\end{array}$ & $\begin{array}{l}\mathrm{N}=105 \\
12(12) \\
38(38) \\
20(20) \\
29(29)\end{array}$ \\
\hline
\end{tabular}

10 years, family medicine organizations such as Society for Teachers of Family Medicine (STFM) and American Academy of Family Physicians (AAFP) have made statements that recognize abortion care as part of family medicine's scope of practice. ${ }^{8,9}$

Despite chair respondents' inclusion of abortion care within family medicine's scope of practice, our survey suggests that chairs are not prepared for potential impacts of CFP. When subspecialties enter the medical landscape, it is not uncommon for family physicians to face regulations and policies that seek to limit their scope of practice, particularly when there is overlap between the skills in the subspecialty and in family medicine. For example, family medicine educators reported difficulty obtaining hospital privileges for maternity care in institutions where obstetricians and gynecologists $(\mathrm{Ob} /$ Gyns) controlled this process due to barriers such as high procedural numbers and/or fellowship training. ${ }^{10}$

Abortion care is an aspect of CFP that may be particularly vulnerable to practice restrictions. As of June 1, 2020, 40 states have some physician requirements around abortion care. ${ }^{11}$ An example of these regulations includes a requirement that abortions can only be performed by a licensed physician and not by advanced practice clinicians. ${ }^{11}$ One state, Mississippi, has a specialty-based restriction on abortion care, requiring that all abortions be performed by an $\mathrm{Ob} /$ Gyn. ${ }^{11}$

It is important that family physicians continue to provide family planning services because of their essential role in our health care safety net. Without family physicians, an additional 1,332 counties would be designated as primary care health personnel shortage areas. ${ }^{12}$ The workforce of community health centers is comprised of $46 \%$ family physicians. ${ }^{13}$ Family physicians also provide the majority of maternity care in rural communities where some family planning services, such as abortion care, are most limited. ${ }^{14}$ Few Ob/Gyns practice in nonmetropolitan areas, with half of all US counties without an American College of Obstetricians and Gynecologists (ACOG) member in practice. ${ }^{15,16}$ Any regulation of family physicians' scope of practice may be particularly detrimental in rural areas.

We found strong and consistent associations between the presence of a faculty champion and chair's report of queried family planning 
Table 2: Knowledge of Complex Family Planning (CFP) and Attitudes Regarding Scope of Practice Among Chair Respondents

\begin{tabular}{|l|c|}
\hline \multicolumn{1}{|c|}{ Knowledge/Attitude Measure } & $\mathbf{n}(\%)$ \\
\hline Aware of CFP subspecialty & $\mathrm{N}=88$ \\
Yes & $7(8)$ \\
\hline Agrees that below service is part of scope of family medicine: & $84(98) \mathrm{N}=86$ \\
Complex contraceptive counseling & $85(98) \mathrm{N}=87$ \\
Pregnancy options counseling & $79(91) \mathrm{N}=87$ \\
First trimester miscarriage management & $67(77) \mathrm{N}=87$ \\
Pregnancy termination by medication abortion* & $52(60) \mathrm{N}=87$ \\
Pregnancy termination by uterine aspiration & $\mathrm{N}=83$ \\
\hline Would advocate to protect scope of practice? & $48(48)$ \\
Yes, for all above services & $2(2)$ \\
Yes, but not for pregnancy termination (medication abortion) & $12(14)$ \\
Yes, but not for pregnancy termination (uterine aspiration) & $16(19)$ \\
Yes, but not for any pregnancy termination & $5(6)$ \\
Not for any of the above services & \\
\hline
\end{tabular}

*Medication abortion with mifepristone and misoprostol.

Table 3: Odds Ratios of Significant Variables* From Bivariate Analysis on Predicting Chairs Responses Regarding Scope of Practice and Advocacy

\begin{tabular}{|l|c|c|c|c|c|}
\hline & Aware of CFP & $\begin{array}{c}\text { Considers } \\
\text { Miscarriage } \\
\text { Subspecialty } \\
\text { Management Part } \\
\text { of FM Scope }\end{array}$ & $\begin{array}{c}\text { Considers } \\
\text { Medication } \\
\text { Abortion Part } \\
\text { of FM Scope }\end{array}$ & $\begin{array}{c}\text { Considers } \\
\text { Aspiration } \\
\text { Abortion Part } \\
\text { of FM Scope }\end{array}$ & $\begin{array}{c}\text { Would Advocate for } \\
\text { All Family Planning } \\
\text { Services** } \\
\text { as Part } \\
\text { of FM Scope }\end{array}$ \\
\hline $\begin{array}{l}\text { Faculty champion present } \\
\text { (absent [reference]) }\end{array}$ & $2.0(0.0-0.4)$ & $12.8(2.3-69.8)$ & $1.5(0.4-5.6)$ & $4.3(1.5-12.2)$ & $3.0(1.1-8.2)$ \\
\hline
\end{tabular}

*All independent variables (Table 1) were insignificant except for presence of family medicine faculty champion in family planning.

**Contraceptive counseling, pregnancy options counseling, miscarriage management, pregnancy termination with medication, pregnancy termination by uterine aspiration.

services as part of family medicine scope of practice. Many avenues exist for developing necessary faculty champions including a number of postresidency fellowships that specifically support family medicine expertise in family planning. ${ }^{17,18}$ Identifying and supporting interested residents or faculty to participate in these opportunities may be an effective way to mobilize family medicine to meet our patients' family planning needs.

\section{Study Limitations}

The response rate was $54 \%$, although this is consistent with prior CERA surveys. Our respondents are similar in gender, race, and age distribution compared with aggregate national demographic data of chairs provided by Association of Departments of Family Medicine. However, it is likely that chairs of departments with robust family planning services were overrepresented because $17 \%$ of our respondents reported being able to provide abortion care within their main outpatient residency clinic, which is a higher number than expected given that only $5 \%$ of all US family medicine residencies are known to have integrated abortion training. ${ }^{19,20}$ This would lead to an overestimation of attitudes that include family planning and abortion care as part of family medicine's scope of practice. We were unable to assess details about the abortion services available at each institution or in the local region, which would have provided more context for interpretation of our findings.

\section{Conclusion}

In our survey of chairs of US departments of family medicine, nearly all respondents considered complex contraceptive counseling, pregnancy options counseling, and miscarriage management to be part of the scope of family medicine. The majority of respondents also considered abortion care to be within the scope of family medicine. While few chairs knew about the Ob/Gyn subspecialty of complex family planning, most would advocate for inclusion of family planning services, including some type of abortion care, in family medicine's scope of practice. Faculty champions are important to maintaining our scope of practice within family planning to meet our patients' needs.

CORRESPONDING AUTHOR: Address correspondence to Dr Grace Shih, University of Washington, Box 354696, Seattle, WA 981954696. 206-616-5034. Fax: 206-685-0610. ghshih@uw.edu. 


\section{References}

1. Accreditation Council for Graduate Medical Education. Obstetrics and Gynecology Program Requirements and FAQs. https://acgme.org/ Specialties/Program-Requirements-and-FAQsand-Applications/pfcatid/12/Obstetrics $\% 20$ and\%20Gynecology. Accessed June 26, 2020.

2. Accreditation Council for Graduate Medical Education. ACGME Program Requirements for Graduate Medical Education in Complex Family Planning. https://acgme.org/Portals/0/PFAssets/ProgramRequirements/236 ComplexFamilyPlanning_2020-06-13. pdf?ver=2020-06-18-101141-800. Published June 13, 2020. Accessed June 26, 2020.

3. Forcier M, Godfrey E, Gold M, et al. Abortion provision: maintaining scope of practice for primary care providers alongside family planning subspecialists. Presentation at the 2018 Society of Family Planning Annual Forum in New Orleans, LA.

4. Creinin M, Landy U, Schreiber C, Teal S. Implications of complex family planning becoming a medical subspecialty. Presentation at the 2018 Society of Family Planning Annual Forum in New Orleans, LA.

5. Seehusen DA, Mainous AG III, Chessman AW. Creating a Centralized Infrastructure to Facilitate Medical Education Research. Ann Fam Med. 2018;16(3):257-260.

6. Accreditation Council for Graduate Medical Education . Family Medicine Program Requirements and FAQs. https://www.acgme. org/Specialties/Program-Requirements-andFAQs-and-Applications/pfcatid/8/Family $\% 20$ Medicine. Accessed April 19, 2020.
7. Herbitter C, Greenberg M, Fletcher J, Query C, Dalby J, Gold M. Family planning training in US family medicine residencies. Fam Med. 2011;43(8):574-581.

8. Kelly BF, Sicilia JM, Forman S, Ellert W, Nothnagle M. Advanced procedural training in family medicine: a group consensus statement. Fam Med. 2009;41(6):398-404.

9. American Academy of Family Physicians. AAFP Congress of Delegates 2019 Resolutions: Resolution 410. https://www.aafp.org/about/governance/congress-delegates/2019/resolutions2 html. Accessed April 19, 2020.

10. Goldstein JT, Hartman SG, Meunier MR, et al. Supporting Family Physician Maternity Care Providers. Fam Med. 2018;50(9):662-671. doi:10.22454/FamMed.2018.325322

11. Guttmacher institute. An Overview of Abortion Laws. https://www.guttmacher.org/state-policy/ explore/overview-abortion-laws. Accessed June 26, 2020.

12. Fryer GE, Green LA, Dovey SM, Phillips RI Jr. The United States relies on family physicians unlike any other specialty. Am Fam Physician. 2001;63(9):1669.

13. National Association of Community Health Centers. Community Health Center Chart Book. http://www.nachc.org/wp-content/uploads/2018/06/Chartbook_FINAL_6.20.18.pdf Accessed June 26, 2020

14. Young RA. Maternity Care Services Provided by Family Physicians in Rural Hospitals. J Am Board Fam Med. 2017;30(1):71-77.
15. Rayburn WF, Klagholz JC, Murray-Krezan C, Dowell LE, Strunk AL. Distribution of American Congress of Obstetricians and Gynecologists fellows and junior fellows in practice in the United States. Obstet Gynecol. 2012;119(5):1017-1022.

16. Hung P, Henning-Smith CE, Casey MM, Kozhimannil KB. Access To Obstetric Services In Rural Counties Still Declining, With 9 Percent Losing Services, 2004-14. Health Aff (Millwood). 2017;36(9):1663-1671.

17. Reproductive Health Access Project. Reproductive Health Care and Advocacy Fellowship. https://www.reproductiveaccess.org/programs/ fellowship/. Accessed June 26, 2020.

18. Society of Family Planning. The Fellowship in Complex Family Planning. https://societyfp. org/fellowship/. Accessed June 26, 2020

19. Center For Reproductive Health Education In Family Medicine. Family Medicine Residencies with Abortion Training. https://rhedi.org/ resources/residency-training/. Accessed April 2, 2020.

20. National Resident Matching Program. Advance Data Tables 2020 Main Residency Match. https://mk0nrmp3oyqui6wqfm.kinstacdn.com/wp-content/uploads/2020/03/Advance-Data-Tables-2020.pdf. Accessed April 2,2020 . 